\section{Edyrcasaice

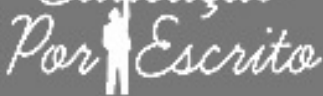

ARTIGO

\section{Editor}

Alexandre Anselmo Guilherme PUCRS, RS, Brasil

\section{Editor Assistente}

Cibele Cheron

PUCRS, RS, Brasi

\section{Editores Associados}

Bruno Antonio Picoli

Universidade Federal da Fronteira Sul, Chapecó, SC, Brasil

Pricila Kohls dos Santos Universidade Católica de Brasília, Brasília, DF, Brasil

Renato de Oliveira Brito

Universidade Católica de Brasilia, Brasilia, DF, Brasil

Elisa Ustarroz

PUCRS, Porto Alegre, RS, Brasil

\section{ISSN 2179-8435}

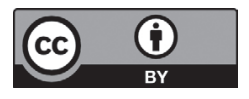

Este artigo está licenciado sob forma de uma licença Creative Commons Atribuição 4.0 Internacional, que permite uso irrestrito, distribuicăo e reprodução seja corretamente citada

\title{
A Internacionalização da Pós-Graduação Brasileira: o caso de uma universidade pública
}

The Internationalization of Brazilian Post-Graduation: the case of a public university

Liliane Gontan Timm Della Méa ${ }^{1}$
Adriana Moreira da Rocha Veiga ${ }^{1}$
Doris Pires Vargas Bolzan ${ }^{1}$

1 Universidade Federal de Santa Maria (UFSM). Santa Maria, Rio Grande do Sul, Brasil.

\section{RESUMO}

Este artigo decorre de estudo fundamentado nas origens da Educação Superior no Brasil, destacando a sua expansão e regulação, para situar o surgimento da Pós-Graduação e de sua avaliação pela CAPES. No contexto da busca por qualificação, este estudo aborda o Sistema Nacional de Avaliação da Educação Superior (SINAES) e o Sistema de Avaliação da Pós-Graduação Brasileira, desenvolvido pela CAPES, nos quais a internacionalização aparece como referência máxima de qualificação. Com base nesse fundamento, a demanda por internacionalização pode ser considerada como sendo o mais forte impacto na conceituação de Programas de Pós-Graduação. O estudo, ainda, objetiva identificar a demanda por internacionalização nos Programas de Pós-Graduação da Universidade Federal de Santa Maria (UFSM), avaliados pela CAPES com conceitos iguais ou superiores a 5, tendo como foco os cursos de doutorado. Utilizou-se o método de estudo de caso qualitativo, analisando-se os documentos de área e a ficha de avaliação dos cursos, bem como as percepções dos coordenadores/gestores no tocante à internacionalização. Os resultados identificam a grande preocupação dos Programas em serem internacionalizados, por meio do desenvolvimento de sua excelência no fortalecimento de parcerias internacionais, intercâmbios, capacitação do corpo docente em pós-doutoramento, capacitação do corpo discente em estágios de curta duração no exterior e, principalmente, no aumento das publicações internacionais. Pretende-se fornecer subsídios à tomada de decisões, por parte dos gestores, para a manutenção, o aperfeiçoamento e o fortalecimento da UFSM e de seus cursos de pós-graduação.

Palavras-chave: Internacionalização da Educação; Avaliação da Pós-Graduação; Sistema Nacional de Avaliação da Educação Superior.

\section{ABSTRACT}

This study is based in the origins of College Education in Brazil, highlighting its expansion and regulation in order to situate the rise of the Post-Graduation and its evaluation made by the agency CAPES. In the context 
of pursuing qualification, it's addressed the National Evaluation System of Higher Education (SINAES) and the Evaluation System of Brazilian Post Graduation, developed by CAPES, in which the internationalization is mentioned as a qualification benchmark. Based in these elements, the demand for internationalization can be considered as one of the most meaningful impact in the evaluation of Post-Graduation Program. This study aims to identify the demand for internationalization in the Post-Graduation Programs of UFSM, graded 5 or above by CAPES. The focus of the study was the Doctoral Courses. The qualitative method of case study was used and the documents of the area, the evaluation form and the interviews conducted with the Coordinators/ Managers regarding internationalization were analyzed. The results identified that there is a great concern in the Programs in becoming internationalized, through the development of its excellence in the strengthening of international partnerships, exchange programs, qualification for its faculty with post-doctoral courses and short term internships abroad and especially in the increasing of its international publications. It is intended to provide subsidies to the decision making for maintenance, perfecting and strengthening of the institution and its Post-Graduation Courses.

Keywords: Internationalization of Education. Evaluation Post Graduation. National System for the Evaluation of Higher Education.

\section{Introdução}

$\mathrm{N}$

o cenário globalizado das relações humanas e institucionais do Século XXI, a internacionalização é uma exigência, sem a qual a formação universitária tenderia a enfraquecer a sua referência como diferenciadora nos diferentes campos profissionais. A internacionalização da universidade brasileira representa desafio importante às Instituições de Ensino Superior (IES), gerando expectativas e metas de aplicação, acompanhamento e gestão de ações efetivas, tanto na graduação quanto na pós-graduação.

Embora a internacionalização envolva diferentes conceituações, neste estudo, optamos pela definição de Pedrozo (2009), o qual a compreende como sendo o processo de inclusão do global, do internacional e do intercultural nos currículos, no processo de ensino/aprendizagem, na pesquisa, na extensão e na cultura organizacional da universidade, trazendo à comunidade acadêmica uma diversidade de conceitos, ideologias e princípios contemporâneos, ainda que preserve as suas origens e motivações próprias.

Segundo o autor supracitado, o maior objetivo das IES ao serem internacionalizadas, salvo a diversidade de conceitos, ideologias e culturas, tende ao fortalecimento do ensino, pesquisa, extensão, gestão e estrutura organizacional, contribuindo com a qualificação de seus técnicos, docentes e discentes e, ainda, ampliando a produção 
de conhecimento, bem como a sua inserção e difusão na comunidade internacional. Em suma, a internacionalização emerge no bojo das políticas e estratégias das IES, para que estas se mantenham e se fortaleçam no cenário globalizado, sem, entretanto, representar apenas um modismo da nossa época.

A escolha desse tema para o estudo de campo, que cotejou os achados apresentados neste artigo, decorreu da percepção da importância do tema para a nossa própria Instituição, a Universidade Federal de Santa Maria (UFSM), portanto, uma universidade pública federal - e para outras congêneres. Assim, a temática principal deste estudo problematiza a demanda por internacionalização dos Programas de Pós-Graduação (PPG), avaliados pela Coordenação de Aperfeiçoamento de Pessoal de Nível Superior (CAPES) ${ }^{1}$ no período entre 2010 e 2012.

Consequentemente, a investigação foi desenvolvida a partir da questão: como se configura a demanda por internacionalização dos Programas de Pós-Graduação da UFSM, avaliados pela CAPES com conceito igual ou superior a 5? O objetivo geral foi "analisar a demanda por internacionalização dos Programas de Pós-Graduação da UFSM, avaliados pela CAPES com conceito igual ou superior a 5". Desdobrando, os objetivos específicos foram: "identificar como a política educacional do Brasil considera a internacionalização, em termos de documentos de área da CAPES"; "verificar como são avaliados, externamente à UFSM, os Programas de Pós-Graduação da UFSM, sob a ótica da internacionalização"; e "compreender a perspectiva dos seus gestores quanto à internacionalização dos doutorados". O estudo articulou, portanto, três pontos de referência: Sistema Nacional de Avaliação da Pósgraduação, Internacionalização e Desenvolvimento Profissional Docente.

Delimitado o recorte temático, desenvolvemos o texto a partir de dois eixos: o metodológico, apresentando o cenário investigativo e a incursão no campo de estudo e o descritivo-interpretativo, expondo, ao mesmo tempo, o campo teórico-conceitual e o corpus da pesquisa, ou seja, os achados junto aos Programas de Pós-Graduação da UFSM, cursos de doutorado com conceito CAPES igual ou superior a 5, cursos conceituados tendo como horizonte a sua qualidade e excelência.

\section{Metodologia e incursão no cenário investigativo}

Atualmente, a UFSM possui cinquenta e quatro (54) Programas de Pós-Graduação distribuídos em nove (9) grandes áreas do conhecimento. O cenário da pesquisa configurou-se a partir dos PPG com cursos de doutorado, avaliados pela CAPES com conceito igual ou superior a 5, nos quais a internacionalização é requisito essencial para

\footnotetext{
Coordenação de Aperfeiçoamento de Pessoal de Nível Superior (CAPES): Agência de fomento que visa à melhoria da pós-graduação brasileira, através de avaliação, divulgação, formação de recursos e promoção da cooperação científica internacional.
} 
alcançar ou manter os conceitos mais elevados no referido sistema de avaliação. Os PPG selecionados para o estudo apresentam a seguinte configuração:

- Área de Ciências Agrárias I - 03 PPG com conceito 5 (Agronomia, Ciências dos Solos e Engenharia Florestal);

- Área de Medicina Veterinária - 01 PPG com conceito 6 (Medicina Veterinária);

- Área de Zootecnia/Recursos Pesqueiros - 01 PPG com conceito 5 (Zootecnia);

- Área de Química - 01 PPG com conceito 7 (Química);

- Área de Ciências Biológicas II - 01 PPG com conceito 5 (Bioquímica Toxicológica);

- Área de Engenharias IV - 01 PPG com conceito 5 (Engenharia Elétrica);

- Área de Linguística, Letras e Artes - 01 PPG com conceito 5 (Letras).

O estudo de caso caracterizou-se no âmbito da pesquisa qualitativa, sendo esta, conforme Godoy (1995), uma abordagem que parte de questões ou focos de interesses amplos, tornando-se mais diretos e específicos no transcorrer da investigação. O tipo da pesquisa permitiu o estudo de caso dos PPG da UFSM e o recorte do cenário nos cursos de doutorado, avaliados pela CAPES com conceito igual ou superior a 5. Isso se justifica, de acordo com Yin (2005), pelo fato desse tipo de investigação contribuir para o conhecimento existente, acerca dos fenômenos individuais, organizacionais, sociais, políticos e grupais, além de outros fenômenos relacionados.

A organização da coleta previu vários procedimentos metodológicos, sendo realizada em quatro etapas, com estratégias e instrumentos diferenciados em cada uma delas:

- Documentos de área, ou seja, diretrizes de avaliação propostas pela CAPES, para a apreciação de cada área do conhecimento, classificadas e hierarquizadas em quatro níveis: grande área, área, subárea e especialidades, abrangendo do mais geral ao mais específico; documentos de área, pesquisados no site da CAPES e que formam o conjunto de diretrizes e critérios de avaliação para as áreas de conhecimento.

- Fichas de avaliação de cada curso de doutorado, avaliado pela CAPES com conceito igual ou superior a 5. Essas fichas têm como subsídios as informações cedidas pelos gestores dos cursos, no Sistema Coleta CAPES, através do Aplicativo Coleta de Dados CAPES ${ }^{2}$, um sistema informatizado desenvolvido com o objetivo de coletar informações dos cursos de mestrado, doutorado e mestrado profissional, integrantes do Sistema Nacional de Pós-Graduação. A alimentação desse sistema consiste no tabelamento dos resultados, expressos nas fichas de avaliação, nas quais é apresentada a avaliação geral de cada curso, explicitando, a cada item de avaliação, o seu resultado. Tais fichas são a fundamentação para

\footnotetext{
2 O Aplicativo Coleta de Dados CAPES seria substituído, em 27/03/2014, pela Plataforma Sucupira, desenvolvida pela CAPES em parceria com a
} Universidade Federal do Rio Grande do Norte (UFRN). 
atribuir os conceitos de cada curso, constituindo o seu fortalecimento ou seu descredenciamento junto à CAPES.

- Entrevistas com os gestores de curso, realizadas com o seu consentimento, em Termo de Consentimento Livre e Esclarecido (TCLE). O roteiro das entrevistas semiestruturadas foi elaborado pela autora, inspirado no Seminário Institucional de Avaliação e Planejamento da Pós-Graduação da UFSM, citado no parágrafo anterior. Esta quarta etapa foi pautada nos itens de avaliação do Seminário e nas expectativas do gestor com relação à internacionalização de seu curso. As entrevistas foram transcritas e analisadas, sendo desenvolvido um quadro analítico, para a visualização das principais referências sobre a internacionalização. Identificamos, também, quais as dificuldades enfrentadas, pelos Programas, para o atendimento da demanda por internacionalização, não somente exigida pela CAPES, como também necessária ao desenvolvimento da área científica do curso e da Instituição.

Nas duas primeiras etapas da pesquisa, o estudo envolveu análise documental. Nos documentos estudados, foi realizada a análise de conteúdo, com destaque aos pronunciamentos que se referiam à problemática da internacionalização. Também, foi utilizada a análise de conteúdo do teor das entrevistas com os gestores transcritas, sendo enfatizadas as declarações que diziam respeito a essa mesma problemática. As categorias utilizadas para a análise de conteúdo foram: a proposta do Programa, corpo docente, atividade de pesquisa, produção intelectual, atividades de formação, destinos dos egressos, ambiente interno, infraestrutura e inserção social, além dos pontos fortes e fracos e das metas de cada variável.

\section{As bases conceituais e os achados do estudo}

A base compreensiva da temática foi buscada nas origens da Educação Superior no Brasil, destacando a sua expansão e regulação, a fim de situar o surgimento da pós-graduação e suas avaliações pela CAPES. A busca por qualificação aponta o Sistema Nacional de Avaliação da Educação Superior (SINAES), bem como o Sistema da Avaliação da Pós-Graduação Brasileira, desenvolvido pela Coordenação de Aperfeiçoamento de Pessoal de Nível Superior (CAPES) - a qual mantém mecanismos de credenciamento, manutenção e fortalecimento dos cursos de pós-graduação -, sistemas nos quais a internacionalização aparece como referência máxima de qualificação. A partir disso, a matriz teórica conceitual aborda a internacionalização como critério de avaliação da pós-graduação e como desafio das Instituições de Ensino Superior (IES).

A Educação Superior, no Brasil, surgiu tardiamente, em 1812, sem, no entanto, se configurar como instituição universitária, mas sim como faculdades para atender à burocracia do Estado e para formar advogados, médicos e 
engenheiros (SCHUCH, 1998). Em 1920, foi instituída a primeira universidade brasileira, a Universidade do Rio Janeiro, reunindo a Escola Politécnica, a Faculdade de Medicina e a Faculdade de Direito. Porém, ainda não existia um projeto de lei, nem uma legislação à altura da importância e da demanda da educação universitária, para o desenvolvimento no país. É uma história demarcada pelo atraso e pelo descaso dos governantes.

A Universidade Federal de Santa Maria, criada em 1960, foi escolhida como cenário para este estudo de caso qualitativo, por ser a maior universidade do interior do Rio Grande do Sul, extremo sul do território brasileiro, e por ter um importante papel no desenvolvimento acadêmico de sua comunidade regional, nacional e internacional, tendo, na origem dos seus Programas de Pós-Graduação, uma proposta de internacionalização. Trata-se de uma Instituição Federal de Ensino Superior, constituída como autarquia educacional de regime especial e vinculada ao Ministério da Educação (MEC).

Nos anos 70, concomitante à implantação do Sistema de Avaliação da Pós-Graduação, a UFSM teve um esforço pioneiro de internacionalização com a iniciativa de criação do primeiro Curso de Pós-Graduação Interamericano (atual Programa de Pós-Graduação em Educação - PPGE), em acordo com o Departamento de Assuntos Educativos da Organização dos Estados Americanos (OEA), destinado aos especialistas de Educação da América do Sul, América Central e América do Norte, visando ao estudo e à pesquisa dos problemas do Ensino Médio na América Latina, como: a aquisição de informações sobre o ensino; a interpretação, análise e elaboração de currículos; a difusão de uma mentalidade experimental na área de Educação e a promoção do intercâmbio entre vários sistemas educacionais dos países americanos (GUTERRES, 2001).

O desafio de internacionalizar foi assumido pela Comissão de Aperfeiçoamento de Nível Superior/CAPES e, para isso, o sistema de pós-graduação fora implantado, ainda nos anos 70, tendo por arcabouço jurídico a Reforma Universitária de 1968, balizada no modelo da universidade americana (cursos estruturados) e com a missão de formar professores e pesquisadores (BRASIL, 2010a). No entanto, segundo Balbachevsky (2005, p. 285), "faltava ao conselho mecanismos adequados e agilidade para acompanhar a explosão de novos Programas que se multiplicavam".

Em 1973, o Ministério da Educação/MEC criou o Conselho Nacional de Pós-Graduação (CNPG), órgão interministerial responsável pela política geral da pós-graduação. Em 1975, as principais agências de financiamento da pós-graduação passaram a ser integradas por esse órgão, entre elas a CAPES e o Conselho Nacional de Desenvolvimento Científico e Tecnológico (CNPq). No CNPG, diversos Planos Nacionais de Pós-Graduação (PNPG) foram elaborados e passaram a dirigir a consolidação e institucionalização da pós-graduação no Brasil, estabelecendo metas e ações para concretizar seus objetivos. No II PNPG, o processo de avaliação da pós-graduação consolida-se sob a coordenação da CAPES. Esse sistema avaliativo, implantado em 1976, permitiu que a CAPES assumisse, gradativamente, a condução da política nacional de pós-graduação. 
Nessa última fase, a Lei de Diretrizes e Bases da Educação Nacional (LDB), Lei no 9394, de 1996, preconizaria uma legislação específica, instruindo o Governo Federal para atender às suas exigências. Segundo Oliven (2002), a LDB introduziu o processo regular e sistemático de avaliação dos cursos de graduação e das próprias IES, condicionando seus respectivos credenciamentos e recredenciamentos ao desempenho mensurado por essa avaliação. Em decorrência de tais regulamentações, a Lei no 1086, de 2004, criou o Sistema Nacional de Avaliação da Educação Superior (SINAES). Nesse sistema, é realizada a construção da avaliação emancipatória, com a proposta de desenvolver uma avaliação formativa que considere as especificidades das IES brasileiras, articulando esforços e instrumentos para avaliar a graduação no Ensino Superior e suas instituições, em um conjunto normativo de sistemas operativos, apesar das lacunas e inconsistências (FELIX, 2008; FONSECA, 2007).

A busca por padrões de qualidade em desenvolvimento tem representado um significativo desafio à Educação Superior brasileira, passando a avaliação a ter um papel preponderante. No Relatório de Gestão da CAPES, o expresidente da CAPES, Jorge Guimarães (BRASIL, 2010b, p. 25) afirma que, "quaisquer que sejam os desdobramentos da reforma, não se pode abrir mão da qualidade. E para haver qualidade é necessário haver avaliação". Segundo o mesmo autor, a qualidade representa o principal critério para a CAPES, dando credibilidade internacional ao sistema de avaliação da pós-graduação do Brasil.

A CAPES vem aprimorando o seu processo de avaliação ao longo dos anos. A partir de 1997, o processo de avaliação passou a atribuir escala numérica de 1 a 7 aos cursos de pós-graduação, atribuindo os conceitos de 6 a 7 aos cursos de padrão internacional. No período de 2004 a 2010, a consolidação dos Programas de Pós-Graduação, aprovados e avaliados pela CAPES, teve foco na aprovação de cursos de doutorado, subindo de 204 para 366 cursos. A base dos principais avanços ocorridos no sistema de avaliação, entre 2004 e 2010, foram a avaliação de novas propostas e a Avaliação dos Programas de Pós-Graduação deste período ${ }^{3}$.

Nesse processo avaliativo, são imprescindíveis as informações fornecidas pelos Programas de Pós-Graduação e a correspondência aos critérios pré-estabelecidos. As comissões de especialistas analisam o desempenho do curso de pós-graduação e atribuem notas dentro da escala de 1 a 7 . A avaliação dos Programas de Pós-Graduação é realizada em dois momentos. O primeiro é o acompanhamento anual, por meio de um sistema informatizado de coleta de dados e alimentado pelos gestores dos Programas de Pós-Graduação. As informações coletadas, ao longo do ano, são fundamentais e decisivas para a Avaliação. Esta é resultante das fichas de avaliação e do desempenho dos Programas de Pós-Graduação, subsidiados pelas informações anuais, prestadas pelos Programas, ao longo de três anos.

3 O Diário Oficial da União de 27 de março de 2017 publicou a Portaria no 59, dispondo sobre o Regulamento da Avaliação Quadrienal 2017, para os anos de 2013 a 2016, para programas acadêmicos e profissionais, o qual abrange período anterior, portanto de Avaliação Trienal. 
Assim, compreendemos que um dos maiores desafios enfrentados pelos Programas de Pós-Graduação é a busca por internacionalização. Ser internacionalizado não significa somente se equiparar aos Centros de Excelência, mas também é um dos quesitos principais para a obtenção dos conceitos máximos da avaliação da CAPES, quais sejam 6 e 7. No entanto, os PPG com conceito 5, para consolidarem a avaliação positiva e avançarem, necessitam trilhar o mesmo caminho. Atingir a classificação de nível 6 ou 7 implica o curso já ter atingido padrão internacional, ou seja, ter sido classificado entre os mais altos níveis de qualificação. Determinado curso, conceituado em 5, dependerá da internacionalização para atingir os conceitos mais altos. O que significa exatamente esse padrão internacional requerido para a qualificação dos PPG?

A internacionalização da pós-graduação segue os padrões estabelecidos pela avaliação da Pós-Graduação no Brasil, cujo alcance classifica um curso para os mais altos níveis de qualificação. A busca da excelência impõe a internacionalização a todos os cursos de pós-graduação. Assim, as classificações de nível 6 e 7 implicam no curso ter atingido padrão internacional. Por outro lado, um curso classificado em nível 5 dependerá da internacionalização para buscar os estratos mais altos de qualificação.

O desafio da internacionalização envolve gestão, docência e desenvolvimento, institucional e docente, sendo um processo dinâmico e necessário, com ações e iniciativas articuladas. Para que ocorram ações integradas, os atores, agências de fomento, organismos internacionais, governos nacionais e internacionais, as IFES e os organismos de investigação e desenvolvimento, devem primar pelo alinhamento e compromisso com a dinamicidade peculiar à internacionalização universitária, como política legitimada pela responsabilidade compartilhada.

Todavia, observa-se limitações no acesso ao cenário internacional, referentes às questões acadêmica e institucional. Questões acadêmicas, referentes aos problemas linguísticos, estruturas curriculares rígidas e reduzida experiência. Quanto às limitações no campo institucional, referem-se aos recursos e a uma política interna efetiva e legitimada de internacionalização. O necessário reconhecimento dos desafios e propostas do incremento da internacionalização está aliado ao compromisso com o desenvolvimento institucional e profissional docente. Isto significa internacionalizar a partir do fortalecimento da instituição para estabelecer parcerias interinstitucionais e redes de pesquisa com competência e agregação de valor reconhecido na relação com outras instituições e pesquisadores.

Quanto à definição do tema de pesquisa, Internacionalização da Educação Superior, muitos autores o descrevem ora como um processo amplo, construído pelas universidades, ora definindo-o como estratégia da globalização. Para Morosini (2006), a internacionalização da Educação Superior exige discernimento: 
[...] é um conceito complexo, com uma diversidade de termos relacionados apresentando diversas fases de desenvolvimento. São citadas: a) dimensão internacional - presente no século XX, que se caracterizava por ser uma fase incidental mais do que organizada; $b$ ) educação internacional: atividade organizada prevalente nos Estados Unidos, entre a segunda guerra mundial e o término da guerra fria, preferentemente por razões políticas e de segurança nacional; e c) internacionalização da Educação Superior, posterior à guerra fria e com características de um processo estratégico ligado à globalização e à regionalização das sociedades e seu impacto na educação superior (MOROSINI, 2006, p. 115).

A internacionalização é importante para as IES, não só na busca por se tornarem centros de excelência, como também visando à própria inserção na comunidade internacional. A internacionalização das IES solidifica uma cultura aberta, fortalecendo o ensino, a pesquisa e a extensão, contribuindo para a qualificação e ampliando a produção do conhecimento e a sua difusão na comunidade internacional.

$\mathrm{Na}$ análise dos documentos de área, identificamos como a política educacional do país considera a internacionalização, em termos de documentos de área, representada pela CAPES. Observamos, nas análises dos documentos de área, que em todos os cursos de pós-graduação, participantes deste estudo, está contida a exigência da internacionalização em sua produção intelectual.

Para o Item V - "Considerações e definições sobre atribuições de conceitos 6 e 7 - inserção internacional" -, são atribuídos os conceitos 6 e 7 aos cursos classificados com conceito 5, primeiro movimento de revisão da avaliação dos PPG, que tenham atendido às condições de desempenho, equivalentes a centros internacionais de excelência na área, e que tenham tido um nível de desempenho altamente diferenciado em relação aos demais Programas da área. Em cada documento de área, foram observados diferentes indicadores de internacionalização, de acordo com a exigência das definições das áreas. Ainda nesta etapa da análise, foram compilados os indicadores que mais se fizeram presentes nas avaliações realizadas nos documentos das áreas estudadas. São eles:

- participação em comitês, diretorias, sociedades e programas internacionais; colaborações internacionais (docência, consultorias, editoria, visitas); participação em intercâmbios e convênios de cooperação, caracterizados por reciprocidade; cooperação e fomento de instituições internacionais (cooperação formal e financiamento no exterior), com intercâmbio de alunos e de docentes; participação discente em atividades e publicações no exterior; realização, organização e participação em eventos internacionais qualificados; produção científica destacada no cenário internacional (avaliar o veículo e a proporção da produção internacional); presença de docentes ou discentes estrangeiros no programa; presença de bolsistas doutores ou em treinamento sabático no programa; prêmios, reconhecimento ou destaque de nível internacional. 
$\mathrm{Na}$ análise do conteúdo das fichas de avaliação, geradas a partir dos relatórios da coleta de dados, informados pelos coordenadores dos PPG no Sistema Coleta CAPES, atualmente o sistema de avaliação é a Plataforma Sucupira $^{4}$, verificamos como os cursos de pós-graduação da UFSM são avaliados externamente, sob a ótica da internacionalização. Nelas, identificamos os itens de avaliação, já apreciados pela CAPES: proposta do Programa: corpo docente; corpo discente, teses e dissertações: produção intelectual; inserção social. A seguir, apresentamos os resultados das fichas de avaliação, por curso e com as respectivas referências da internacionalização.

No Programa de Pós-Graduação em Agronomia, o quesito Corpo Docente indica a existência de parcerias e interações com outros Programas e outras universidades do país e do exterior, assim como no quesito Inserção Social em que há uma efetiva cooperação e intercâmbios sistemáticos e a participação em projetos de cooperação entre Programas.

O Programa de Pós-graduação em Ciência do Solo, quanto ao quesito Corpo Docente, apresenta inúmeras parcerias, intercâmbios e interações com outros Programas e outras universidades do país e do exterior e inserção social; os docentes participam como coorientadores de doutorado na Argélia, além de participarem de projetos de cooperação no exterior. Já, no Programa de Pós-Graduação em Engenharia Florestal, há indicação, no quesito Corpo Docente, de parcerias, intercâmbios e interações com outros Programas e outras universidades do país e do exterior.

No Programa de Pós-Graduação em Medicina Veterinária, nos quesitos Corpo Docente e Inserção social, o Programa aponta a existência de parcerias, intercâmbios e interações com outros Programas e outras universidades do país e do exterior, além da participação efetiva das cooperações, intercâmbios sistemáticos e de projetos de cooperação entre Programas.

No Programa de Pós-Graduação em Zootecnia, as referências de internacionalização são reveladas no quesito Inserção Social, indicando alguns convênios de cooperação nacional, a recomendação de intensificar as ações de inserção internacional, bem como o estímulo aos docentes para estágios pós-doutorais, principalmente no exterior.

O Programa de Pós-Graduação em Química, nos quesitos Proposta do Programa, Produção Intelectual e Inserção Social, apresenta Programas de intercâmbio, elevada produção científica e Programas institucionais de colaboração internacionais. Já, o Programa de Pós-Graduação em Bioquímica Toxicológica indica, no quesito Proposta do Programa, colaborações com outras instituições nacionais e iniciou colaborações internacionais.

O Programa de Pós-Graduação em Engenharia Elétrica exibe referências de internacionalização, no quesito Corpo Docente, com o pós-doutoramento de seus recursos humanos no exterior.

4 A Plataforma Sucupira é uma nova e importante ferramenta para coletar informações, realizar análises e avaliações e ser a base de referência do Sistema Nacional. O documento conceituou, formatou e institucionalizou a pós-graduação brasileira nos moldes como é até os dias de Pós-Graduação (SNPG). A escolha do nome é uma homenagem ao professor Newton Sucupira, autor do Parecer no 977 de 1965 de hoje. 
O Programa de Pós-graduação em Letras indica, nos quesitos Proposta do Programa, Corpo Docente e Inserção social, os convênios internacionais, participação docente em associações internacionais, além de alguns intercâmbios internacionais.

$\mathrm{Na}$ etapa seguinte de análise da pesquisa, apresentamos as perspectivas dos coordenadores/gestores com relação à internacionalização do seu curso. Foram realizadas três perguntas a respeito da sua percepção, na posição de gestor, quanto à internacionalização do seu curso: quais os aspectos/fatores facilitadores da internacionalização? Quais as principais restrições (fatores restritivos) da internacionalização? Quais as perspectivas do fortalecimento da internacionalização? Para complementar as percepções dos gestores, foi acrescido um questionamento sobre as ações desenvolvidas para o incremento da internacionalização. A apresentação e discussão desses resultados resguardou a identidade dos Programas e dos coordenadores, a fim de preservar o anonimato e confidencialidade dos dados.

Nos aspectos facilitadores existentes nos cursos, existem pontos positivos, no sentido da potencialidade que os cursos desenvolvem, destacando-se a existência de contatos como um aspecto facilitador na formação acadêmica no exterior, no esforço de receber estudantes estrangeiros, nas linhas de pesquisas e nos editais da CAPES. Abaixo, seguem alguns excertos, dando voz aos coordenadores:

“[...]. Existe a formação de várias pessoas no exterior. Isto facilita o contato com pesquisadores no exterior.” (Programa 1)

“[...] A qualificação e o reconhecimento que alguns professores têm acabaram desencadeando alguns convênios com alguns países e isso de alguma maneira, cria uma espécie de sequência de contatos que acabam se refletindo nesse processo de internacionalização." (Programa 3)

“[...] Nós temos muito contato de alunos estrangeiros, principalmente latinos, da América Central, mostrando interesse em ser alunos do Programa, principalmente de fazer mestrado e doutorado." (Programa 5)

“[...]. Este ponto forte do Programa tem que ficar saliente, seria essa aproximação, uma dedicação dos professores a receber estudantes estrangeiros.” (Programa 2)

"[...]. Os facilitadores são exatamente as nossas linhas de pesquisa, são pesquisas, são linhas que estão tem gente trabalhando em vários lugares do mundo.” (Programa 7)

“[...] É a grande quantidade de editais que a CAPES tem de convênio, patrocina ou que ela disponibiliza." (Programa 4) 
No sentido de "o que o coordenador/gestor espera como aspectos facilitadores" foram identificados os desejos de ter infraestrutura, política institucional e bolsas. Destacamos os seguintes trechos:

“[...]. Um aspecto fundamental é se nós tivéssemos na nossa universidade, de uma forma organizada é óbvio e planejada, moradia... Eu sei que é algo complicado, mas é facilitador tanto para alunos de pós-graduação como para pesquisadores [...] ter o mínimo de infraestrutura." (Programa 9)

"Eu acho que passa pela política institucional. Se a universidade tem uma política clara sobre isso e que isso se concretize em estimular que esses convênios, esses acordos sejam feitos, que os professores, que os Programas se insiram nas políticas de internacionalização.” (Programa 1)

“[...]. É oferecer bolsas. Oferecer alguma vantagem dentro de projetos, enfim, oferecer oportunidades futuras, profissionais ligados com empresas no Brasil e no exterior, que possam vincular também os projetos que vão ser executados pelos alunos de pós-graduação." (Programa 3)

A segunda pergunta feita aos coordenadores/gestores abordou os fatores restritivos da internacionalização de seus cursos, havendo recorrência quanto à questão do domínio de língua estrangeira. Um dos coordenadores considerou a infraestrutura como aspecto facilitador e restritivo. Afirmam os gestores:

"Nós estamos sem telefone [...] Nossa internet é caótica, [...] Só temos uma funcionária. Então, quer dizer, cobram da gente uma macroatividade e a gente tem uma microinfraestrutura que a instituição precisa resolver." (Programa 7)

“[...]. Ela decorre do domínio da língua estrangeira, que talvez assim para os professores já existe algumas dificuldades." (Programa 6)

Destacamos, quanto ao aspecto da infraestrutura, a posição geográfica, a vontade dos professores, o suporte do departamento e da instituição, a organização didática e a inserção "em cima do pesquisador":

“[...] A saída de um professor para fora, no exterior, mexe com toda a distribuição de encargos didáticos. Alguém tem que assumir as disciplinas desse professor, já que não é possível ter substituto para esse tipo de ação. .... Tu saindo, alguém vai se sobrecarregar.” (Programa 6)

Ainda: 
“[...] A restrição é a chegada a Santa Maria [...] Santa Maria cria uma dificuldade de translado, de movimentação, então, a posição de Santa Maria é, hoje, do ponto de vista de acesso à cidade, um elemento fortemente restritivo para quem vai fazer a escolha." (Programa 1)

Outro gestor expôs:

"Ela começa lá no professor, se o professor não está a fim de se internacionalizar, ou porque não sabe inglês, ou porque não está a fim, ou porque não adianta, tu não vais conseguir internacionalizar nenhum curso e no meu curso às vezes a gente se esbarra um pouco nisso, no professor dizer não.” (Programa 5)

E ainda:

"As principais restrições. Eu acho que isso aí deixa toda responsabilidade da inserção em cima do Pesquisador. Ele tem que providenciar dinheiro. Ele tem que providenciar a infraestrutura. Ele tem que providenciar acomodação. Não existe um programa da universidade favorecendo isto, colocando regras e condições para pessoa favorecer esta inserção." (Programa 3)

Como aspectos restritivos, observamos a legislação, a inexistência de cotas de bolsas e as ações individuais, definidas por iniciativas pessoais, em geral, restringe a inserção do Programa como um todo, vinculada as atividades de grupos de pesquisa coordenados pelos docentes que assino o convênio e o promove. Há uma evidente carência de uma política institucional capaz de sustentar as ações dos PPG. Analisemos os excertos a seguir:

"Aluno estrangeiro vir sem bolsa é difícil... nós não temos bolsa.

[...]. Esbarra na legislação, pois a legislação não permite que se faça editais separados. Vamos supor que tem um critério de seleção para aluno brasileiro e um critério para aluno estrangeiro." (Programa 2)

Ainda:

“[...] as ações individuais. Eu acho muito individual, não se pensa no conjunto... Se isso não tiver pensado como uma ação dentro de um grande projeto, se é só algo que eu consegui pela minha experiência de internacionalização, pela minha relação com as instituições do exterior, eu acho que tem que ser uma política do Programa para poder ter essa cara de internacionalização.” (Programa 9). 
Ressaltamos como aspectos restritivos, na percepção dos coordenadores/gestores, o medo do desafio e o significado de internacionalizar:

"Num segundo momento qual é a percepção que a gente teve? É talvez, assim, aquele medo do desafio de enfrentar uma dificuldade. Então, no momento, que tanto os professores como estudantes estão confortáveis dentro do seu trabalho. Você sair dessa rotina e enfrentar essa dificuldade é um desafio.” (Programa 1)

Nas perspectivas da internacionalização de seus cursos, os entrevistados evidenciaram alguns incrementos, tais como: internacionalização em longo prazo, visibilidade internacional, conscientização da internacionalização, ações de internacionalização e fortalecimentos. Vejamos a seguir:

"Vamos ser um curso com visibilidade internacional e a gente percebeu que isso não é uma tarefa fácil nem rápida e leva um tempo para as coisas acontecerem e elas estão acontecendo.” (Programa 4)

"Eu não acredito que haja perspectivas de se desenvolver isso [a internacionalização] no quadro em que nós estamos hoje. Hoje nós temos uma situação que praticamente $100 \%$ dos alunos de doutorado tem bolsa. Há recursos em relação aos anos passados, há recursos, quero dizer as condições são boas para fazer pós-graduação, mas isso se restringe à clientela tradicional, alunos nossos, brasileiros, possibilidade de inserção de alunos estrangeiros neste contexto é muito pequena." (Programa 2)

Ainda:

“[...] a minha perspectiva é que a gente deveria internacionalizar e trazer professores por mais tempo, trazer professores visitantes, trazer professores para fazer estágio pós-doutoral aqui, ou estágios em laboratórios com mais tempo." (Programa 8)

Os coordenadores/gestores apontaram, ainda, as melhorias de infraestruturas, a contratação de docentes, os fortalecimentos de convênios, o resgate de contatos, a política governamental, a criação de condições, de cultura e tradição de intercâmbios e a transformação interna, via políticas institucionais de estímulo a expansão de ações interinstitucionais, como forma de sustentação de ações localizadas nos PPG.

"Eu vejo a perspectiva já na contratação de professores, pensando nesse lado, que façam a pós-graduação." (Programa 3) 
“[...] Como eu tenho uma grande quantidade de alunos formados e eles estão espalhados por vários locais, inclusive no exterior, a tendência é resgatar estes contatos que já estão ocorrendo e através, principalmente, deste Programa Ciência Sem Fronteiras, articular a duração de intercâmbios." (Programa 5)

"A perspectiva é que nós vamos com a maré. Então se a maré é favorável, isto é, os governos, esperamos que os governos ofereçam planos, esperamos oportunidades.” (Programa 6)

Um dos gestores afirmou, ainda:

“[...] talvez a instituição tenha que estar mais preparada para isto. E o Programa pode até fazer, resolve, mas o problema é que a universidade é a porta, não é o Programa a entrada. Você entra pela universidade, então, neste aspecto a universidade tem dificuldades. Quer dizer, este é o principal fator limitante é esse aí, quer dizer a instituição não está preparada para isso, em todos os aspectos.” (Programa 8)

Nas entrevistas, foi constatado, ainda, que:

"Uma universidade full, plena, completa, aonde nós sabemos o nosso papel e sabemos que o nosso papel é ter relações internas e externas, internas com nós mesmos uma forte ligação interna, mas também forte relação com o mundo se inserindo, tendo essa visão global, mas tendo uma atuação forte local, que é aqui que nós inserimos, tudo isso é feito para nós termos melhores profissionais, melhores professores, melhores servidores e melhores formadores de recursos humanos. É isso que a nossa sociedade precisa.” (Programa 3)

Quanto à perspectiva para o fortalecimento da internacionalização do curso, um dos entrevistados identificou negativamente a sua perspectiva:

"É, tudo gira na mesma história, por exemplo, a minha perspectiva é que os professores não vão aprender inglês, então essa parte da internacionalização que depende do conhecimento da língua não vai acontecer. A minha expectativa, vamos dizer assim, de que o curso avance muito em termos de internacionalização, eu não acredito.” (Programa 6)

Destacamos a qualificação do corpo docente, discente e técnico, a infraestrutura e o domínio de língua estrangeira como os principais fatores limitadores com foco nas perspectivas dos gestores. As principais ações desenvolvidas 
pelos cursos são: a formação de recursos humanos, a manutenção de convênios internacionais e as melhorias nas publicações internacionais.

Apresentamos, a seguir na Figura 1, um panorama geral na perspectiva dos Programas analisados, identificados aleatoriamente com números:

Figura 1. Perspectiva Geral dos Programas sobre as ações de internacionalização.

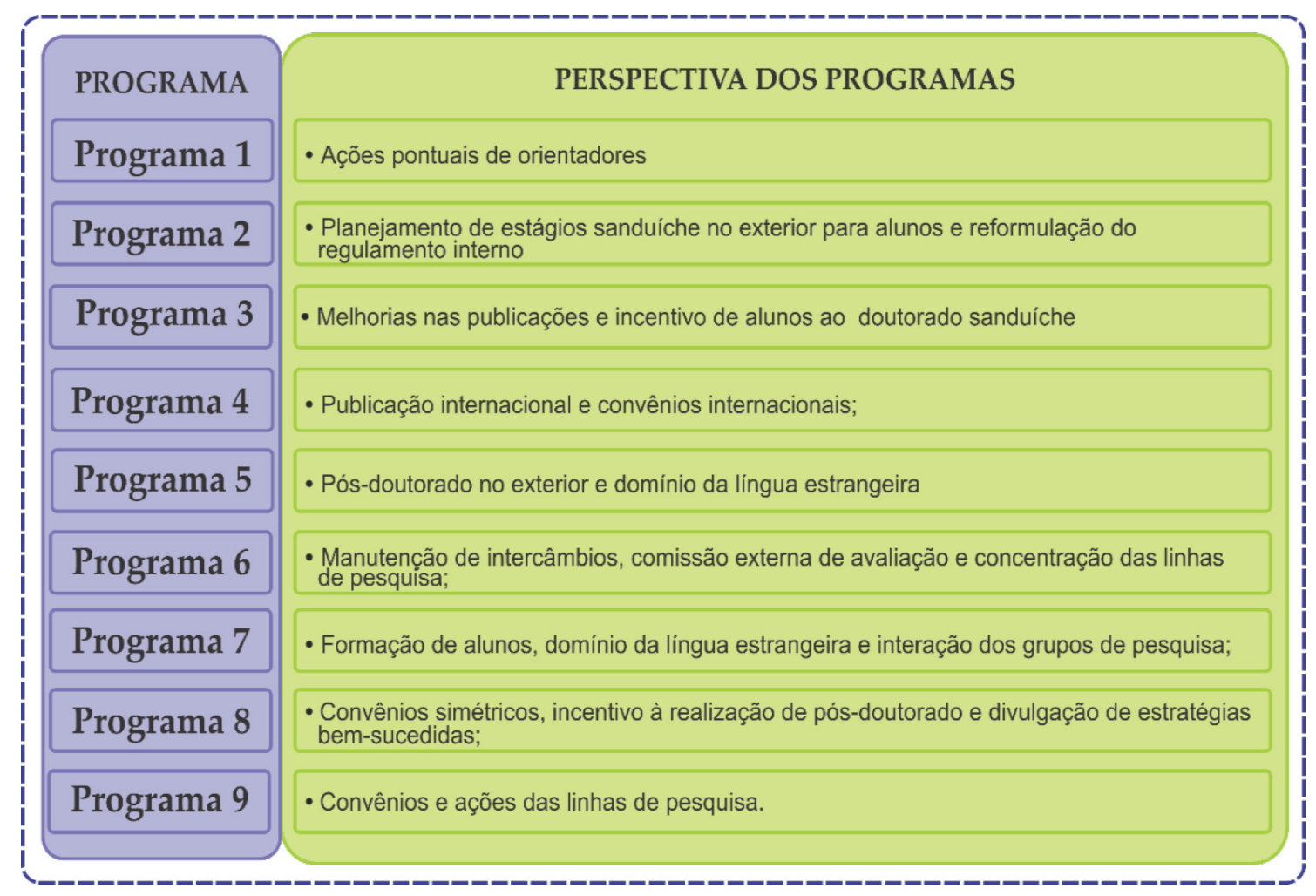

Fonte: (Della Méa, 2013). 
Verificamos na perspectiva dos Programas, a grande preocupação dos cursos com os desafios da internacionalização, portanto com a demanda exigida não só na avaliação externa, mas também nas diretrizes internas. Tal posicionamento está operacionalizado nas inúmeras ações, descritas na Figura 1 pelos gestores dos PPG da Instituição de Ensino Superior/IES ao serem perguntados sobreas perspectivas de expansão das ações de internacionalização no interior dos PPG a partir das políticas da universidade.

\section{Considerações finais}

Teceremos as considerações finais, reportando-nos ao objetivo geral, qual seja "analisar a demanda por internacionalização dos Programas de Pós-Graduação da UFSM, avaliados pela CAPES com conceito igual ou superior a 5". Também, aos objetivos específicos de "identificar como a política educacional do Brasil considera a internacionalização, em termos dos documentos de área da CAPES; "verificar como são avaliados, externamente à UFSM, os Programas de Pós-Graduação da UFSM, sob a ótica da internacionalização"; e "compreender a perspectiva dos seus gestores quanto à internacionalização dos cursos doutorados".

A análise da avaliação externa, realizada nos documentos de área e nas fichas de avaliação da CAPES, demonstrou a exigência e responsabilidade, no tocante à internacionalização dos cursos da UFSM, principalmente no que se refere à sua produção intelectual e inserção internacional, com vistas à busca de desempenho equivalente aos dos centros internacionais de excelência.

$\mathrm{Na}$ análise das entrevistas, realizadas com os coordenadores/gestores dos cursos, foi percebida a existência de mais fatores restritivos do que aspectos facilitadores, para que se incremente a internacionalização, existindo, no entanto, expectativas para que isso aconteça. Os entrevistados acreditam que as ações que estão sendo desenvolvidas venham ao encontro do fortalecimento da internacionalização nos seus Cursos e da demanda de produção, exigida pela CAPES.

A UFSM demonstra preocupação em criar mecanismos de instrumentalização para os seus Programas de Pós-Graduação, a fim de que estes atinjam a excelência acadêmica. Um desses mecanismos foram os Seminários de Avaliação e Planejamento desses Programas. A Instituição pontua, ainda, visão estratégica na consolidação de seus Programas de Pós-Graduação, por meio do seu Plano de Desenvolvimento Institucional (PDI).

Como sugestões para contribuir neste importante processo de internacionalização dos cursos de pós-graduação da UFSM, registramos: realização de seminários de sensibilização, com a comunidade acadêmica, sobre essa temática; conscientização dos corpos discente e técnico sobre o que é internacionalizar, o porquê de e como internacionalizar os cursos de pós-graduação e a instituição como um todo. Outra sugestão é o planejamento e o investimento em uma 
política institucional de internacionalização permanente, baseados na sua infraestrutura, abrangendo aspectos, como ensino de línguas em todos os segmentos, moradias para estrangeiros, oferta de bolsas como forma de expansão de fomento à internacionalização, central técnica para atender às demandas de editais, em todos os quesitos exigidos, e reformulação de sua regulamentação interna, para atendimento das demandas da internacionalização.

Esperamos que esses resultados e reflexões possam contribuir para o reconhecimento da importância da internacionalização nos cursos de pós-graduação, bem como seja uma forma de claramente apoiar as instituições que buscam a sua qualificação, apresentando subsídios à tomada de decisões, à manutenção e aperfeiçoamento de estruturas e à busca de excelência internacional.

Ainda, com o intuito de contribuir para uma política de internacionalização da UFSM, acreditamos que este estudo traz indicadores para a realização de um diagnóstico da situação dos programas de pós-graduação, permitindo que se situem e se projetem no cenário local, regional, nacional e internacional.

Por outro lado, esta pesquisa apontou a necessidade de uma investigação mais abrangente e apurada acerca da relevância de uma política efetiva de internacionalização, para a busca institucional de uma posição elevada no cenário internacional da Educação Superior, o que conjugaria, em nosso entendimento, o desenvolvimento institucional e o de seus pesquisadores como agentes nas/das relações interinstitucionais, para além das fronteiras brasileiras.

\section{Referências}

BALBACHEVSKY, E. A pós-graduação no Brasil: novos desafios para uma política bem-sucedida. In: BROCK. C.; SCHWARTZMAN, S. Os desafios da educação no Brasil. Rio de Janeiro: Nova Fronteira, 2005, p. 275-304.

BRASIL. Instituto Nacional de Estudos e Pesquisas Educacionais Anísio Teixeira. Sistema Nacional de Avaliação da Educação Superior: da concepção à regulamentação. Brasília, DF: INEP, 2004. https://doi.org/10.1590/s2176-6681/371614642

BRASIL. Ministério da Educação. Coordenação de Aperfeiçoamento de Pessoal de Nível Superior. Plano Nacional de Pós-Graduação - PNPG 2011-2020. Brasília, DF: MEC:CAPES, 2010a. https://doi.org/10.5433/1679-0383.2014v35n2p49

BRASIL. Ministério da Educação. Coordenação de Aperfeiçoamento de Pessoal de Nível Superior. Relatório de Gestão $2004-2010$. Brasília, DF: MEC:CAPES 2010b. https://doi.org/10.4000/books.iheal.1748

DELlA MÉA, L. G. T. A Internacionalização da Pós-Graduação: Um Estudo de Caso da Universidade Federal de Santa Maria. Dissertação (Mestrado em Gestão das Organizações Públicas) - Universidade Federal de Santa Maria, Santa Maria, 2013. https://doi. org/10.21840/siic/147814 
FELIX, G. T. Reconfiguração dos modelos de universidade pelos formatos de avaliação: efeitos no Brasil e Portugal. 2008. Tese (Doutorado) - Universidade Federal do Rio Grande do Sul, Porto Alegre, 2008. https://doi.org/10.29289/259453942018v28s 1059

FONSECA, D. G. da F. Implicações do exame nacional de desempenho dos estudantes (ENADE) nos processos avaliativos internos do curso de educação física do IPA 2007. 2007. Tese (Doutorado) - Universidade do Vale do Rio dos Sinos, Porto Alegre, 2007. https:// doi.org/10.5327/z1679443520180200

GODOY, A. S. Introdução à pesquisa qualitativa e suas possibilidades. Revista de administração de empresas, São Paulo, v. 35, n. 2, p. 57-63, 1995. https://doi.org/10.1590/s0034-75901995000200008

GUTIERRES, C. R. J. A faculdade interamericana de educação: projeto multinacional de aperfeiçoamento de pessoal especializado em educação, 1970/1977. Santa Maria: PPGE:UFSM, 2001.

MOROSINI, M. C. Estado do conhecimento sobre internacionalização da educação superior - Conceitos e práticas. Educar,

Curitiba, n. 28, p. 107-124, 2006. https://doi.org/10.1590/s0104-40602006000200008

OLIVEN, A. SOARES, M. S. A. (org.). A Educação Superior no Brasil. Brasília, DF: CAPES, 2002. 304 p.

PEDROZO, N. O Setor de Relações Internacionais das IFES e suas interfaces na universidade. In: ASSOCIAÇÃO NACIONAL DE DIRIGENTES DAS INSTITUIÇÕES DE ENSINO SUPERIOR/ANDIFES. Palestra. Brasília, DF, 2009. https://doi.org/10.18830/

issn.1679-0944.n19.2017.04

SCHUCH JR, V. F. Educação e universidade: raízes históricas e situação brasileira. Santa Maria: VF Schuch Junior, 1998.

YIN, R. K. Estudo de Caso: planejamento e métodos. Porto Alegre: Bookman, 2015.

Recebido em: 04/11/2018.

Aprovado em: 17/12/2019.

Publicado em: 31/12/2019.

\section{Endereço para correspondência:}

Liliane Gontan Timm Della Méa

Universidade Federal de Santa Maria (UFSM)

Centro de Educação - Programa de Pós-Graduação em Educação

GEU (Grupo de Estudos sobre Universidade)/REDE GEU

Av. Roraima, 1000, Prédio 16, Sala 3175 - Campus Universitário

97105-900, Santa Maria, RS, Brasil 


\section{Autoras:}

Liliane Gontan Timm Della Méa

Técnica-Administrativa em Educação do Centro de Educação. Especialista em Gestão Universitária pela UFRGS. Mestre em Gestão das Organizações Públicas; Doutora em Educação; Graduada em Letras - Português, sendo toda a sua formação acadêmica na IFES. Atua junto à coordenação do GEU (Grupo de Estudos sobre Universidade) e Coordena o GEIES (Grupo de Estudos da Internacionalização na Educação Superior), dinamizando o convênio com a UFRGS na IFES e junto ao Núcleo de Internacionalização do Centro de Educação. Membro da Rede GEU e da Rede Sul Brasileira de Investigadores de Educação Superior.

Orcid: http://orcid.org/0000-0001-8611-8146

E-mail: 1ilianedm09@gmail.com

Adriana Moreira da Rocha Veiga

Professora do Departamento de Fundamentos da Educação da IFES atua no Programa de Pós-Graduação em Educação (professora e Coordenadora Substituta) e no Programa de Pós-Graduação em Políticas Públicas e Gestão Educacional. Pedagoga e Especialista em Psicopedagogia pela Faculdade de Filosofia, Ciências e Letras (atual Universidade Franciscana). Mestre em Educação Brasileira pela IFES. Doutora em Educação pela Unicamp. Líder do GEU/IFES e do GPKOSMOS - Grupo de Pesquisas sobre Educação na Cultura Digital e Redes de Formação. Membro da Rede GEU e da Rede Sul Brasileira de Investigadores de Educação Superior. Orcid: http://orcid.org/0000-0002-5804-3375

E-mail: adrianaufsm@gmail.com

Doris Pires Vargas Bolzan

Professora Titular do Departamento de Metodologia do Ensino da IFES atua no Programa de Pós-Graduação em Educação e no Programa de Pós-Graduação em Políticas Públicas e Gestão Educacional. Mestrado em Educação e Doutorado em Educação pela UFRGS. Bolsista Produtividade/PQ2. Líder do Grupo de Pesquisa Formação de Professores e Práticas Educativas: educação básica e superior- (GPFOPE 2002). Coordenadora do Programa de Políticas Educativas NEPI/AUGM

Membro da Rede Sul Brasileira de Investigadores de Educação Superior, da rede GEU, associada a LASA-Latin American Studies Association e a ILADEI- Rede Latino-americana de Estudos sobre a Infância.

Orcid: http://orcid.org/0000-0002-1704-008X

E-mail: dbolzan19@gmail.com 